\title{
SURGICAL TECHNIQUES IN PARTIAL DEAFNESS TREATMENT
}

\author{
Henryk Skarzynski ${ }^{1,2}$, Monika Matusiak ${ }^{1,2}$, Anna Piotrowska ${ }^{1,2}$, Piotr H. Skarzynski ${ }^{1,3,4}$
}

${ }^{1}$ Institute of Physiology and Pathology of Hearing, ul. Zgrupowania AK "Kampinos" 1, 01-943 Warsaw, Poland

${ }^{2}$ World Hearing Center, Mokra 17, Kajetany 05-830 Nadarzyn, Poland

${ }^{3}$ Institute of Sensory Organs, Mokra 1, Kajetany 05-830 Nadarzyn, Poland

${ }^{4}$ Medical University of Warsaw, Otolaryngology and Rehabilitation Clinic of the Physiotherapy Division of the Second Faculty of Medicine, Żwirki i Wigury 61, 02-091 Warsaw, Poland

Corresponding author: Monika Matusiak MD, PhD, Otorhinolaryngosurgery Clinic, World Hearing Center, Mokra 17, 05-830 Nadarzyn, Poland, e-mail: m.matusiak@ifps.org.pl

\begin{abstract}
Background: To maximise the success of cochlear implantation, optimal placement of the electrodes inside the cochlea is required. Hearing preservation also means that intracochlear spaces must be approached in a way that avoids traumatising inner ear structures.

Material and Methods: In order to examine this issue a literature search was performed targeting articles on surgical techniques used in partial deafness cochlear implantation. The aim was to evaluate the advantages and shortcomings of each technique.

Results: In cochlear implantation two main approaches to the middle ear have been described: mastoidectomy/posterior tympanostomy and suprameatal. Two approaches to the inner ear are in use: cochleostomy and round window.

Conclusions: From temporal bone studies and clinical work some general conclusion can be drawn: straight arrays should use round window insertion, and precurved arrays should use cochleostomy.
\end{abstract}

Key words: hearing preservation • cochleostomy • round window approach

\section{TÉCNICAS QUIRÚRGICAS EN LA SORDERA PARCIAL}

\section{Extracto}

Antecedentes: Para maximizar el éxito de los implantes cocleares, se requiere una colocación óptima de los electrodos dentro de la cóclea. Para la conservación del oído, los espacios intracocleares deben ser abordados de un modo que evite traumatizar las estructuras del oído interno.

Materiales y Métodos: Para examinar este tema, se buscó en la bibliografía los artículos sobre las técnicas quirúrgicas usadas para la implantación coclear en la sordera parcial. El objetivo era evaluar las ventajas y desventajas de cada técnica.

Resultados: En la implantación coclear se han descrito dos abordajes principales del oído medio: mastoidectomía/timpanotomía posterior y suprameatal. Se utilizan dos abordajes del oído interno: cocleostomía y ventana redonda.

Conclusiones: Se puede sacar una conclusión general de los estudios del hueso temporal y el trabajo clínico: los electrodos rectos deben ser insertados desde la ventana redonda, y para los precurvados debería emplearse la cocleostomía.

Palabras clave: conservación del oído • cocleostomía • abordaje desde ventana redonda

\section{ХИРУРГИЧЕСКИЕ ТЕХНИКИ ПРИ ЧАСТИЧНОЙ ГЛУХОТЕ}

\section{Резюме}

Предпосылки: Чтобы максимизировать успех кохлеарной имплантации, требуется оптимальное размещение электродов в улитке. Сохранение слуха также значит, что надо подходить к интракохлеарным пространствам таким образом, чтобы избежать травмы структур внутреннего уха.

Материалы и Методы: Чтобы рассмотреть этот вопрос, мы провели обзор литературы, исследуя статьи по хирургическим техникам, использованным в кохлеарной имплантации при частичной глухоте. Цель - оценить преимущества и недостатки каждой из техник. 
Результаты: В кохлеарной имплантации описаны два главных подхода к среднему уху: мастоидэктомия/ задняя тимпаностомия и надпроходной метод. Используются два подхода к внутреннему уху: кохлеостомия и круглое окно.

Заключение: На основании изучений височных костей и клинической работы можно сделать следующее общее заключение: в случае прямых матриц должна использоваться имплантация круглых окон, а в случае изогнутых матриц - кохлеостомия.

Ключевые слова: сохранение слуха • кохлеостомия • подход круглого окна

\section{Introduction}

Optimal electrode placement inside the cochlea is needed to maximise the success of cochlear implants. The standard surgical procedure of cochlear implantation involves mastoidectomy, posterior tympanostomy with a facial recess approach to the middle ear, and finally an approach to the cochlea itself [1-4]. Hearing preservation requires minimising the extent of surgical intervention in terms of duration of the procedure and the amount of dissection of the temporal bone [2].

\section{Background}

Development of the partial deafness treatment concept involve two main aspects: preserving inner ear structure and inhibiting or reducing a kind of foreign body reaction process inside the cochlea which leads to the spread of chronic inflammation [3,5-8]. Because even minor disturbance of inner ear structures can promote the spread of inflammatory processes, as well as having other side effects, the whole concept has now turned towards a new surgical philosophy. Hearing preservation requires approaching intracochlear spaces with the aim of avoiding the traumatisation of inner ear structures [3,9-11]. At the same time, there has been an intense development of cochlear implant technology, the lifespan of the elderly has been extended, and the selection criteria for qualifying as a "partially deaf" patient has been expanded; the result is that there is a growing number of individuals who could be candidates for cochlear implantation. Revisions of cochlear implants are also now occurring [5].

\section{Methods}

A literature search was performed to review articles on surgical techniques in hearing preservation. We broadly aimed in this review to assess current surgical approaches to hearing preservation in cochlear implantation. PubMed searches were conducted for the period 2003 to 2012. We searched for the terms "hearing preservation surgery" and "partial deafness".

Exclusion criteria were defined as: hearing preservation in vestibular schwannoma surgery, petrous cholesteatoma, endolymphatic sac and duct surgery, hearing preservation in intratympanic drug delivery, genetic etiology of hearing loss, and molecular methods for hearing loss diagnosis.

\section{Results}

The following sections present results of the survey. Sections 1 and 2 describe surgical techniques, subdivided into middle- and inner-ear approaches. Special attention is paid to cochleostomy and the round window approach: the first is widely used and well represented in the literature; the second has greater significance for the future development of partial deafness treatment.

\section{Surgical procedures in the middle ear approach}

\subsection{Mastoidectomy - posterior tympanostomy}

The surgical aspect of partial deafness treatment consists of the standard cochlear implantation procedure, a method originally described by House in 1976 for treatment of profound sensorineural hearing loss in post-lingually deafened patients $[2,12]$. However, to protect the residual function of the cochlea, particularly from exposure to additional acoustic trauma due to drilling, the whole surgical process needs to be shortened as much as possible $[2,10]$. The first step is antromastoidectomy - opening of the mastoid process cavity to give access to the middle ear $[2,11]$. To preserve hearing, a mastoidotomy rather than a mastoidectomy was proposed by Skarzynski as the first step of his 6-step surgical procedure for partial deafness treatment $[2,13]$. Dissection is continued to visualise the incus body, using its short process as a landmark of the facial nerve canal position and performing a posterior tympanotomy, which is the second step of the Skarżynski 6-step procedure $[2,11,13]$ (Figure 1).

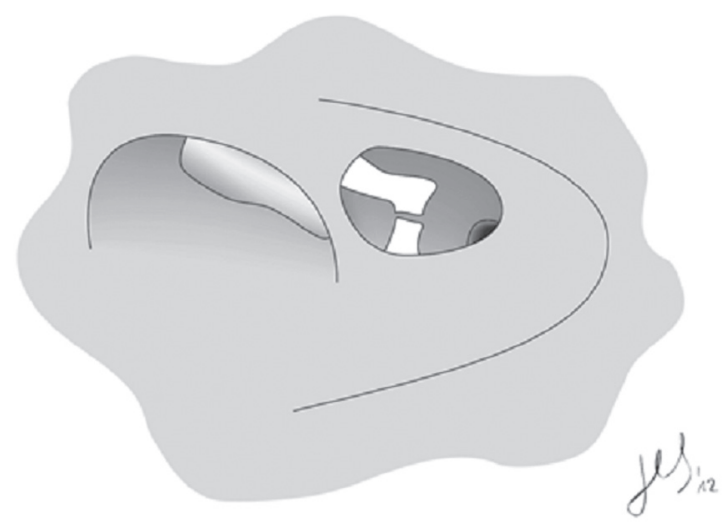

Figure 1. Posterior tympanotomy with exposure of the round window. Step 2 of the Skarzynski 6-step surgical procedure for partial deafness treatment.

All aspects of individual anatomical variations should be considered at this stage: the position of the middle fossa dura and sigmoid sinus which determines the angle of 
visual access to the middle ear, a possible high position of the facial nerve canal, orientation of the ossicles, promontory, and round window niche in the tympanic cavity, and possible variations in configuration of the middle ear [14]. The standard approach to the middle ear is a facial recess approach, giving two possible ways to reach the cochlea: promontory cochleostomy or the round window approach [18].

\subsection{Suprameatal approach}

An alternative to the standard surgical approach for cochlear implantation is Kronenberg's suprameatal approach, a method gaining in popularity mainly because it lowers the risk of facial nerve and chorda tympani injury $[16,17]$. Unlike the standard surgical procedure described in section 1.1 , there is no mastoidectomy and posterior tympanotomy, so this approach allows the duration of the surgical procedure to be shortened; it also avoids extensive drilling of the mastoid and lowers associated risks of acoustic trauma. The electrode wire is located in a groove in the posterior wall of the external ear canal, and it approaches the middle ear at an angle 30 degrees or more higher than in the standard approach, another factor leading to reduced intracochlear trauma [15]. The position of the electrode wire in the outer ear canal, which exposes it to possible mechanical trauma, is one of the shortcomings of this approach [17].

\section{Surgical techniques for the inner ear approach}

There are two main ways to reach the cochlea: cochleostomy and through the round window membrane.

\subsection{Cochleostomy}

Originally, the round window technique was used for regular cochlear implantation in cases of profound sensorineural hearing loss. Technical parameters of electrode arrays in those times, like stiffness and size, were a big limitation of this approach $[14,18]$. Surgeons moved on to the less natural, but easier to perform, cochleostomy approach after considering various aspects of the anatomy of the basal turn of the cochlea: they wanted to avoid the risk of striking the modiolus wall, traumatising the spiral lamina, or disrupting the basilar membrane $[4,17]$.

In the hearing preservation concept, several options were proposed in order to optimise conditions for preserving intracochlear structures [19]. If located anteriorly and inferiorly to the round window, cochleostomy is an approach which gives relatively easy access to scala tympani and provides a way of controlling the trajectory of the electrode insertion within the basal turn of the cochlea and keeping it in line with its axis, especially when performing deep insertions with soft arrays [8,9,20-22,]. This provides a considerable degree of atraumaticity, even with stiffer arrays, and prevents dislocation of other inner ear compartments like scala vestibuli and the cochlear duct $[4,19,21,23$,].

However, Briggs, Tykocinski, and $\mathrm{Xu}$ in their temporal bone insertion studies showed that there was a tendency for the array to take a position along the outer wall of scala tympani within the basal turn when using the cochleostomy approach, thereby giving a greater risk of tearing the spiral ligament or disrupting the basilar membrane; even the subendosteal position of the array can be affected due to the distribution of insertion forces vectors in this part of the cochlea [18]. Kiefer, Gstoettner, Baumgartner and colleagues proposed another variation of cochleostomy in which its position is $1 \mathrm{~mm}$ caudal to the midline of the round window [22]. Brettini, Forli, and Passetii also advocated a round window cochleostomy [23].

In all these versions of cochleostomy, the risk of acoustic trauma of inner hair cells due to drilling remains, there is still a risk of disrupting the osseous spiral lamina or basilar membrane, and care in managing the endosteum is needed. Keeping the endosteum intact as long as possible before inserting the array is a feature of the best surgery and diminishes the risk of aggravating tissue reaction around the array [9]. There are some critical points connected with the insertion itself: careful control of any bleeding and incorporation of bone dust is critical, and special attention needs to be paid to the application of suction $[11,19,21,22]$. The rate of insertion needs to be slow to reduce forces, prevent folding-over of the electrode tip, and to diminish disturbances of perilymph [21].

\subsection{Round window approach}

As in cochleostomy, the way to reach the round window niche in the tympanic cavity from the mastoidectomy side is the facial recess approach $[15,20]$. In aiming for the round window niche, one has to keep in mind that sometimes its location and position requires enlargement of the posterior tympanostomy and its extention more inferiorly. In children especially, a high position of the facial nerve can be a considerable obstruction $[14,24]$. The round window approach means, first identifying the round window niche in the tympanic cavity and then the round window membrane itself $[2,13,15,19]$. In some cases this may be difficult due to considerable variability in the size and shape of the round window and also in the orientation of the round window niche $[15,25]$. Very often access to the round window membrane is obstructed by a bony overhang of the posterior labia of the round window niche, and sometimes of its antero-inferior edge, which requires some additional dissection and preparation and takes more time and effort $[4,11,15]$. Another anatomical circumstance that can mislead the surgeon's eye is the presence of some soft tissue and fibrosis covering the round window niche, which can imitate the membrane itself [15].

The next step is an approach to scala tympani through the round window membrane. It is the $3^{\text {rd }}$ step in Skarzynski's 6-step procedure for partial deafness treatment (Figure 2).

This approach ensures an exact, direct access to scala tympani without any drilling of the cochlea's bony capsule. Unlike the cochleostomy approach, which brings some risk of missing scala tympani, the round window approach allows for precise insertion of the array into the right scala [13]. This access is step 4 in Skarzynski's 6-step surgical procedure $[2,10,13]$ (Figure 3 ). The ease of reaching the inner ear through the round window has been shown in a number of temporal bone dissection studies (e.g., Lenarz et al., Briggs, Tykocinski and Xu, Skarzynski et al.) $[2,5,9,19,15,26]$. 


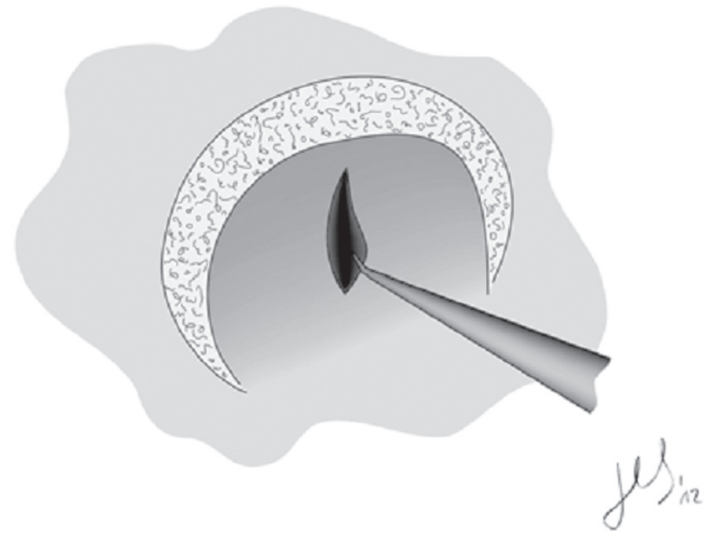

Figure 2. After its identification, the round window membrane is punctured and incised ready for electrode insertion. It is step 3 of Skarzynski's 6-step surgical procedure for partial deafness treatment.

Associated with the development of this approach, a new design philosophy for the electrode array and its technical parameters comes into play. As efforts started to be made to preserve the existing function of the organ of Corti (allowing for acoustic as well as electric hearing), more flexible and thinner electrodes were needed $[4,11,13,19]$. This development has reduced problems of insertion angle and the array's trajectory during the initial phase of insertion $[4,19]$. Since the position of a soft electrode array inserted through the round window into scala tympani is naturally more peri-modiolar in the basal turn, this assures better coupling between the electrodes and the spiral ganglion dendrites in this part of cochlea [7,23]. Souter, Briggs, Wright and Roland in their temporal bone study recommended the round window approach for straight arrays [4].

After insertion of the array into scala tympani, the next step is to fix the array into position in the round window to prevent it from dislodging, slipping out, or turning around $[2,4]$. In time, soft tissue will form some fibrosis around the array, stabilising its position $[4,11,17]$.

\section{Discussion and Conclusions}

With new technologies and the development of molecular methods, in the future we may expect the introduction of new ways of treating sensorineural hearing loss and even possible regeneration of the organ of Corti [27]. For this reason function protection, when operating next to working cochlea, is a natural guideline in cochlear implantation in patients with partial deafness.

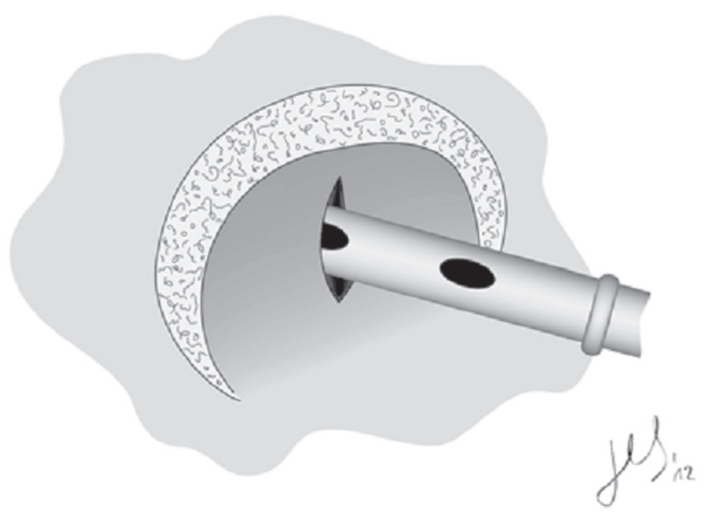

Figure 3. Insertion of the electrode array into scala tympani. It is step 4 of Skarzynski's 6-step surgical procedure for partial deafness treatment.

In an analysis of over 900 subjects with functional residual hearing, Skarzynski et al. evaluated how well pre-operative hearing compared to post-operative pure tone audiometry hearing thresholds, taking into account the specific inner ear approach used $[2,5,13]$. The analysis showed the superiority of the round window approach over cochleostomy in terms of hearing preservation rate, and pointed to a new direction in how surgery should be conducted $[2,5]$. In particular, to maintain inner ear structures and their function, surgery should be meticulous, with tailored intervention from skin incision to skin closure, and special attention paid to electrode array insertion $[5,9,13,19]$. The round window approach respects the variability of human anatomy, giving the surgeon the feeling of following natural guidelines.

Avoiding structural trauma requires a few major precautions. The best surgical technique to preserve hearing respects individual anatomy, carefully considers insertion depth, and uses appropriate parameters in the design of the electrode array $[9,13,19,23]$. Today there is a choice between straight or precurved electrodes and soft or flexible ones. Depending on individual hearing status and anatomy, a surgeon can also choose one of two approaches to the cochlea. To qualify for cochlear implantation, the criteria have been extended to individuals with substantial low frequency hearing, and a growing number of patients qualify for complementation of their high and mid frequency hearing by means of electric stimulation. These developments call for a surgical technique that has minimal invasiveness and trauma potential. With growing access to new technological solutions, implantable hearing prostheses will continue to improve; accordingly, to match the new opportunities such advances bring the implantation process must be made both shorter and less invasive.

\section{References:}

1. Gantz BJ, Turner C, Gfeller KE: Acoustic plus Electric Speech Processing: Preliminary Results of a Mulitcenter Clinical Trial of the Iowa/Nucleus Hybrid Implant. Audiol Neurotol, 2006; 11(Suppl.1): 63-68
2. Skarzynski H, Lorens A, Piotrowska A, Skarzynski PH: Hearing preservation in partial deafness treatment. Med Sci Monit, 2010; 16(11), CR555-62

3. Skarzynski H, Lorens A: Partial deafness treatment. Cochlear Implants Int, 2010; 11(Suppl.1): 29-41 
4. Souter MA, Briggs RJS, Wright CG, Roland PS: Round window Insertion of precurved perimodiolar electrode arrays: how successful is it? Otol Neuroto, 12010; 32: 58-63

5. Skarzynski H, Lorens A, Piotrowska A, Anderson I: Preservation of low frequency hearing in partial deafness cochlear implantation (PDCI) using the round window surgical approach. Acta Otolaryngologica, 2007; 127: 41-48

6. Skarzynski H, Lorens A, D'Haese P et al: Preservation of residual hearing in children and post-ligually deafened adults after cochlear implantation- an initial study. J Otorhinolaryngol Relat Spec, 2002; 64(4): 247-53

7. Gstoettner W, Kiefer J, Baumgartner WD et al: Hearing preservation in cochlear implantation for electric acoustic stimulation. Acta Otolaryngol, 2004; 124: 348-52

8. Punte AK, Vermeire K, Van de Heyning P: Bilateral electric acousticstimulation: a comparison of partial and deep cochlear electrodeinsertion. A longitudinal case study. Adv Otorhinolaryngol, 2010; 67: 144-52

9. Lenarz T, Stóver T, Buechner A et al: Temporal bone results and hearing preservation with a new straight electrode Audiol Neurotol, 2006; 11(Suppl.1): 34-41

10. Skarzynski H, Lorens A, Zgoda $\mathrm{M}$ et al: Atraumatic round window deep insertion of cochelar electrodes. Acta Otolaryngol, 2011; 131(7): 740-49

11. Carlson ML, Colin LW, Driscoll W et al: Implication of minimizing trauma during conventional cochlear implantation. Otol Neurotol, 2011; 32: 962-68

12. House WF: Cochlear implants. Ann Otol Rhinol Laryngol, 1976; 85: 1-93

13. Skarzynski H: Ten years experience with a new strategy of partial deafness treatment. Journal of Hearing Science, 2012; 2: $11-18$

14. RolandPS, Wright OG, Isaacson B: Cochlear implant electrode insertion: the round window revisited. Laryngoscope, 2007; 117: 1397-402

15. Postelmans JTF, van Sponses E, Grolman W et al: An evaluation of preservation of residual hearing using suprameatal approach for cochlear implantation: can this implantation technique be used for preservation of residual hearing? Laryngoscope, 2011; 34: 1444-47
16. Kronenberg J, Baumgartner WD, Migirov L et al: The suprameatal approach: an alternative surgical approach to cochlearimplantation. Otol Neurotol, 2004; 25: 41-45

17. Shapira Y, Sultan AA, Kronenberg J: The insertion trajectory in cochlear implantation - comparison between two approaches. Acta Oto-Laryngologica, 2011; 131: 958-61

18. Briggs RJ, Tykocinski $\mathrm{M}, \mathrm{Xu} J$ et al: Comparison of round window and cochleostomy approaches with a prototype hearing preservation electrode. Audiol Neurotol, 2006; 11: 42-48

19. Gantz BJ, Turner CW: Combining acoustic and electric hearing. Laryngoscope, 2003; 113: 1726-30

20. Cosetti M, Roland T: Cochlear implant electrode insertion Operative Techniques in Otolaryngology, 2010; 21: 223-32

21. Bruce IA, Homewood Mills Bates JE, Melling C et al: Hearing preservation via a cochleostomy approach and deep insertion of a standard length cochlear implant electrode. Otol Neurotol, 2011; 34: 1444-47

22. Kiefer J, Gstoettner W, Baumgartner W et al: Conservation of low-frequency hearing in cochlear implantation. Acta Otolaryngol, 2004; 124: 272-80

23. Berrettini S, Forli F, Passetti S: Preservation of residual hearing following cochlear implantation: comparison between three surgical techniques. J Laryngol Otol, 2008; 122: 246-52

24. Wysocki J, Skarzynski H: Cochleostomy during the ontracochelar implantation. Anatomicla conditions in children and adults. Otolaryngol Pol, 1998; 52(6): 689-94

25. Verbist BM, Joemai RMS, Briaire JJ et al: Cochlear coordinates in regard to cochlear implantation: a clinically individually applicable 3 dimentional CT based method. Oto 1 Neurotol, 2010; 31: 738-44

26. Skarzynski H, Lorens A, Matusiak M et al: Partial deafness treatment with the nucleus straight research array cochlear implant. Audiol Neurootol, 2012; 17(2): 82-91

27. Carlson ML, Driscoll CL, Gifford RH et al: Implications of minimizing trauma during conventional cochlear implantation Otol Neurotol, 2011; 32: 962-68 